Check for updates

Cite this: RSC Adv., 2018, 8, 38270

Received 16th August 2018

Accepted 9th November 2018

DOI: $10.1039 / \mathrm{c} 8 \mathrm{ra06867d}$

rsc.li/rsc-advances

\title{
Physical modification of biochar to expose the inner pores and their functional groups to enhance lead adsorption $\uparrow$
}

\begin{abstract}
Alaa Hasan Fahmi, (D) ${ }^{\text {ab }}$ Abd Wahid Samsuri, (D) *a Hamdan Jol ${ }^{a}$ and Daljit Singh ${ }^{a}$
Biochars have been successfully used to treat wastewater and contaminated soils. The efficiency of biochar as a biosorbent of heavy metals can be increased by reducing the particle size, exposing the inner pores and their functional groups. In this study, the empty fruit bunch biochar (EFBB) of oil palm was separated into three particle sizes, fine (F-EFBB $<50 \mu \mathrm{m}$ ), medium (M-EFBB 250-500 $\mu \mathrm{m}$ ) and coarse (C-EFBB > 2000 $\mu \mathrm{m})$ to compare their physical and chemical characteristics and their adsorption capacity for lead. Results revealed that the F-EFBB had greater surface area and exposed more micropores compared to the other particle sizes. Similarly, the F-EFBB had the most oxygen containing functional groups, CEC, and negative charges as measured by the zeta potential. The F-EFBB had the highest adsorption capacity for $\mathrm{Pb}$, followed by $\mathrm{M}$-EFBB and $\mathrm{C}$-EFBB with the lowest. Therefore, the F-EFBB are able to adsorb more heavy metals as compared to M-EFBB and C-EFBB, as suggested by the more favourable physical and chemical characteristics.
\end{abstract}

\section{Introduction}

Biochar has been used as an option to treat heavy metal contamination in soil and water. ${ }^{1}$ Biochar is a carbon-rich product made by charring feedstocks, mainly from the biological by-products in the absence of air. The use of biochar as a biosorbent for the treatment of wastewater and soil contaminated with heavy metals is a better alternative to conventional high cost sorbents such as activated carbon. ${ }^{2}$

Existing research suggests the types of feedstock and pyrolysis temperature are responsible for the structure and properties of biochars. ${ }^{3}$ The porosity, functional groups and surface area of biochars are controlled by production temperature, heating rate, pressure, retention time and ash content. ${ }^{4}$ The biochar produced at low temperature pyrolysis $\left(<500{ }^{\circ} \mathrm{C}\right)$ has higher cation exchange capacity (CEC), ${ }^{5}$ nitrogen content, exchangeable bases and number of functional groups. ${ }^{6}$ The low temperature biochar production also produces a higher yield ${ }^{7}$ while consuming less energy. ${ }^{8}$ However, the biochar produced at a low temperature has low $\mathrm{pH}$ and surface area and contains unexposed functional groups which results in biochar with low adsorption capacity for heavy metals and organic pollutants. ${ }^{9}$

${ }^{a}$ Department of Land Management, Faculty of Agriculture, Universiti Putra Malaysia, 43400 UPM Serdang, Selangor, Malaysia. E-mail: samsuriaw@upm.edu.my; Tel: $+60389474864$

${ }^{b}$ Department of Soil Science and Water Resources, College of Agriculture, University of Diyala, Diyala, Iraq

$\dagger$ Electronic supplementary information (ESI) available. See DOI: $10.1039 / \mathrm{c} 8 \mathrm{ra} 06867 \mathrm{~d}$
The resulting low surface area and unexposed functional groups of biochar produced at low temperatures can be attributed to pore closing or blockage by volatile materials ${ }^{\mathbf{1 0}}$ and ash, ${ }^{\mathbf{1 1}}$ or to the bottle neck phenomenon. ${ }^{12}$ Therefore, the properties of biochar must be improved before it can be used efficiently as a biosorbent for heavy metals.

Biochar pore size and surface functional groups are important properties affecting its efficiency as an adsorbent of heavy metals. ${ }^{11,12}$ A biochar's high adsorption capacity for metals can be attributed to the functional group, zeta potential and CEC. ${ }^{13}$ The adsorption of metals by biosorbents can be via complexation between the metals and various functional groups on the surface of the biosorbents, or electrostatic attractions between metal cations with negative charges and the functional groups. ${ }^{14}$ According to Mohan et al. ${ }^{15}$ functional groups can be found throughout the biochar matrix. Therefore, crushing the biochar will expose the functional groups which can adsorb the metals. Moreover, the heavy metal adsorption by biochar can take place both on the surface (outer pores) and inside the pore structure of the biochar (inner pores). ${ }^{16}$ According to the terminology used by the International Union of Pure and Applied Chemistry (IUPAC), pores can be divided into three sizes: micropores $(<2 \mathrm{~nm})$, mesopores $(2-50 \mathrm{~nm})$, and macropores $(>50 \mathrm{~nm}) .{ }^{17}$ The micropores and mesopores are more important in the adsorption of heavy metals ${ }^{3}$ and are located mainly inside the pore structure of the biochar, hence the term inner pores. It has been suggested that the macropores $(>50$ $\mathrm{nm}$ ) behave as a channel that transports heavy metals to the micro- and mesopores because adsorption occurs only at the walls and not in the void volume of the pores. ${ }^{10,17}$ If the 
macropores channelling the heavy metals to the meso- and micropores are blocked, the adsorption capacity of biochar for heavy metals will be reduced. Several previous studies have suggested if the macropores are blocked, the ability of the inner pores to adsorb metals will be reduced. ${ }^{4}$

Crushing biochar into smaller particle sizes has been used to improve the adsorptive capacity of biochar for heavy metals. However, all previous studies used biochars with particle sizes much larger than $50 \mu \mathrm{m}$ in treating wastewater and contaminated soils and the authors found particle size had very little effect on the adsorption of heavy metals. ${ }^{18,19}$ One possible reason is the bottlenecks in the biochars were still present even though the particle size had been reduced. Therefore, crushing the biochars into particle sizes much larger than $50 \mu \mathrm{m}$ did not increase the adsorption capacity of the biochars because the inner pores of the biochar porous structure were still not exposed. Dieguez-Alonso ${ }^{\mathbf{1 2}}$ mentions the biochar particle size should be at least two orders of magnitude larger than the maximum size of the expected pores. For instance, if we expect pore diameters up to $100 \mathrm{~nm}$, the minimum particle size of the biochar should be $>10 \mu \mathrm{m}$. Therefore, to expose micro $(<2 \mathrm{~nm})$ and mesopores $(2-50 \mathrm{~nm})$ the size selected should be $<50 \mu \mathrm{m}$ to increase the destruction of macropores (less important) and expose the maximum number of micro and mesopores on the surface of the biochar. Therefore, this study offers a relatively simple and environmentally friendly method of biochar modification to enhance its capacity to adsorb heavy metals. The biochar was physically modified by pulverizing it into a very fine particle size and compared its $\mathrm{Pb}$ adsorption capacity with coarser particle biochars.

To be best of our knowledge, there is no reported study on the effects of biochar particle size reduction to $<50 \mu \mathrm{m}$ on its properties, especially on the exposure of inner pores and surface functional groups. Therefore, in this study an empty fruit bunch biochar (EFBB) produced by low temperature pyrolysis $\left(250{ }^{\circ} \mathrm{C}\right)$ was crushed to a particle size $<50 \mu \mathrm{m}$ and its physicochemical properties and adsorption capacity for lead $(\mathrm{Pb})$ compared with the same EFBB having larger particle sizes (0.25-0.5 $\mathrm{mm}$ and $>2 \mathrm{~mm})$. We hypothesised that crushing the EFBB to $<50 \mu \mathrm{m}$ would expose the inner pores and their surface functional groups and as a result increase its adsorption capacity for $\mathrm{Pb}$. The objective of this study was to determine the effect of physical modification of EFBB by crushing its physicochemical properties, especially those related to adsorptive capacity for heavy metals.

\section{Materials and methods}

\section{Chemicals and reagents}

All the chemical reagents were of analytical grade and the solutions were prepared using a Milli-Q system (Direct-Q ${ }^{\circledR} 3$ UV) of ultrapure water $\left(18.2 \mathrm{M} \Omega \mathrm{cm}^{-1}\right.$ electrical resistivity). Analytical grade sodium nitrate $\left(\mathrm{NaNO}_{3}\right)$ with $99.99 \%$ purity was purchased from Sigma-Aldrich (USA) while barium chloride $\left(\mathrm{BaCl}_{2} ; 98.00 \%\right.$ purity), sodium bicarbonate $\left(\mathrm{NaHCO}_{3} ;>99.70 \%\right.$ purity), sodium carbonate $\left(\mathrm{Na}_{2} \mathrm{CO}_{3} ; 99.90 \%\right.$ purity), sodium hydroxide (99.00\% purity), hydrochloric acid ( $\mathrm{HCl} ; 37.00 \%$ ACS grade), nitric acid $\left(\mathrm{HNO}_{3} ; 65.00 \%\right.$ GR grade) and phenolphthalein $\left(\mathrm{C}_{20} \mathrm{H}_{14} \mathrm{O}_{4} ; 99.00 \%\right.$ ACS grade $)$ were purchased from Merck (Germany).

\section{Biochar samples}

Empty fruit bunch biochar (EFBB) was purchased from the Malaysian Palm Oil Board (MPOB), located in Bangi Lama, Selangor, Malaysia. The biochar was prepared using lowtemperature $\left(250{ }^{\circ} \mathrm{C}\right)$ slow pyrolysis. The biochar was brought to the laboratory where it was lightly crushed using a pestle and mortar and then passed through metal sieves (laboratory test sieve Endecotts Ltd., United Kingdom) to separate into two different particle sizes; coarse EFBB ( $>2 \mathrm{~mm}$; C-EFBB) and medium EFBB (0.25-0.5 mm; M-EFBB). The fine EFBB $(<50 \mu \mathrm{m}$; F-EFBB) was produced by milling the EFBB with a planetary milling machine (Pulverisette 4 Vario-Planetary Mill) set at $1200 \mathrm{rpm}$ for $3 \mathrm{~h}$. All three biochar samples (C-EFBB, M-EFBB and F-EFBB) were kept at room temperature prior to analysis.

\section{Physical analysis}

Scanning electron microscopy and energy-dispersive X-ray (EDX) analysis. The surface morphology analysis of all the three EFBB samples was conducted using the Field Emission Scanning Electron Microscopy (Fei Nova Nanosem 230 FESEM, Netherland) attached to an Energy Dispersive X-ray Spectroscopy (EDX) (Oxford Instrument X-MAX, UK). The EDX was used to determine the elements on the surface of the EFBB samples.

Surface area analysis. The surface area of the EFBB samples was determined by $\mathrm{N}_{2}$ adsorption at $77 \mathrm{~K}$, with the BrunauerEmmett-Teller (BET) technique using a surface area analyser (Autosorb-1, Quantochrome Instruments, USA). Prior to the analysis, the EFBB samples were degassed at $200{ }^{\circ} \mathrm{C}$ for 9 hours. The multipoint BET method was used to calculate the total surface area. The $t$-plot method was used to calculate the micropore surface area. The pore volumes were determined from their desorption isotherms using the Barrett-JoynerHalenda (BJH) method. The total pore volume was determined using a single $\mathrm{N}_{2}$ adsorption point at a $P / P_{0}$ of $\sim 0.97$.

\section{Chemical analysis}

pH and EC. The pH of the EFBB samples was measured according to Savova et $a l^{20}$ by weighing a $4.0 \mathrm{~g}$ sample in a conical flask and mix with $100 \mathrm{~mL}$ of deionised water. The flask was covered with a watch glass and boiled for $5 \mathrm{~min}$. The mixture was left to cool at room temperature and the supernatant was decanted. The $\mathrm{pH}$ of the supernatant was determined using a Metrohm ${ }^{\circledR} 827 \mathrm{pH}$ meter. The electrical conductivity (EC) of the EFBB samples was measured by soaking the sample in Millipore water at a solid/water ratio of $1: 5(\mathrm{w} / \mathrm{v})$ and agitated for $24 \mathrm{~h}$. The reading was recorded using a CON $700 \mathrm{EC}$ meter (Eutech Instruments, USA).

Ash content. Ash content of the biochar samples was determined by the dry combustion method. A $5.0 \mathrm{~g}$ sample was placed in a crucible and heated at $500{ }^{\circ} \mathrm{C}$ for $8 \mathrm{~h} .{ }^{21}$ Then, the crucible was cooled to room temperature and reweighed. The ash content was calculated as follows: 


$$
\text { Ash content }(\%)=\frac{\text { weight of ash }(\mathrm{g})}{\text { dry mass of biochar }(\mathrm{g})} \times 100 \%
$$

Elemental contents. The elemental content in the samples was determined according to the method used by McGrath and Cunliffe. ${ }^{22}$ Additional details can be found in the ESI. $\dagger$

Total CHNS. The total carbon, hydrogen, nitrogen and sulphur content in the samples was determined using the CHNS 628 analyser (Leco®, USA).

Quantitative determination of surface acidic functional groups. The surface acid functional groups of the EFBB samples were determined by the Boehm titration method. ${ }^{21,22}$ Additional details can be found in the ESI. $\dagger$

Cation exchange capacity. The cation exchange capacity (CEC) of the EFBB samples was determined by a compulsive exchange method ${ }^{23}$ as simplified by Shen et al. ${ }^{18}$ The details are found in the ESI. $\dagger$

Surface functional groups. The presence of surface functional groups in the biochar samples was determined using the Spectrum 100, Perkin-Elmer FTIR spectrometer with a resolution of $4 \mathrm{~cm}^{-1}$ operating in the range of $300-4000 \mathrm{~cm}^{-1}$.

Zeta potential. The zeta potential value of the samples was determined by weighing a $0.02 \mathrm{~g}$ sample in a $250 \mathrm{~mL}$ conical flask containing $100 \mathrm{~mL}$ of $0.1 \mathrm{M} \mathrm{NaCl}$ solution. The $\mathrm{pH}$ of the resulting suspension was adjusted at intervals of $\mathrm{pH} 2$ to 10, using either $0.025 \mathrm{M} \mathrm{HCl}$ or $0.025 \mathrm{NaOH}$. A bath-type sonicator with a $300 \mathrm{~W}$ power supply line and set at $40 \mathrm{kHz}$ for 120 minutes at $30{ }^{\circ} \mathrm{C}$ was used to disperse the suspension ultrasonically. The suspension was left undisturbed for 24 hours and thereafter, electrophoresis mobility measurements were conducted using a Zetasizer Nano Malvern® zeta potential metre.

$\mathrm{X}$-ray diffraction. The X-ray diffraction (XRD) was conducted after adsorption $\mathrm{Pb}$ by different particle sizes of biochar using Bruker D8 Advance X-ray Diffractometer, Germany. The sample was prepared by placing its powder in a sample holder. Thereafter, the sample holder was arranged in the diffractometer which operated at $40 \mathrm{kV}$ voltage and the sample was scanned from $20-100^{\circ}$ with a speed of $1^{\circ}$ per minute.

Batch adsorption studies. The adsorption experiment was carried out at room temperature in sorbate $\mathrm{Pb}$ (II) ion to determine the adsorption characteristics of the EFBBs. The adsorption isotherms of $\mathrm{Pb}$ were obtained by weighing $0.1 \mathrm{~g}$ of EFBBs into Falcon tubes (3 replicates). Thereafter, a $40 \mathrm{~mL}$ solution containing specific concentrations of $\mathrm{Pb}$ were added to the Falcon tubes. With or without biochar the $\mathrm{Pb}$ concentration levels of 0,5 , 10, 50, 100, 200, 300 and $500 \mathrm{mg} \mathrm{L}^{-1}$ were individually evaluated. All samples were equilibrated for $24 \mathrm{~h}$ on a rotary shaker (KASI KSI-200L, Korea). After settling, a $40 \mathrm{~mL}$ aliquot of the supernatant was filtered through a $0.45 \mu \mathrm{m}$ syringe filter and then analysed for Pb concentrations using ICP-OES (Perkin Elmer Optima 8300 DV, USA). The samples were analysed in triplicate. The removal percentage of $\mathrm{Pb}$ (II) ions at equilibrium was calculated using the following equation:

$$
\operatorname{Removal}(\%)=\frac{C_{0}-C_{\mathrm{e}}}{C_{0}} \times 100
$$

where $C_{0}$ and $C_{\mathrm{e}}$ are concentrations of the $\mathrm{Pb}$ ion initially and at equilibrium, respectively. The $\mathrm{Pb}$ ion adsorbed $\left(\mathrm{mg} \mathrm{g}^{-1}\right)$ on different EFBBs treatments was calculated for each sorbent using the following equation:

$$
Q_{\mathrm{e}}=\frac{\left(C_{0}-C_{\mathrm{e}}\right) \times v}{w}
$$

where $Q_{\mathrm{e}}$ is the amount of adsorbed $\mathrm{Pb}$ ion $\mathrm{mg} \mathrm{g}^{-1}, v$ is the applied $\mathrm{Pb}$ ion solution volume (L) and $w$ is the adsorbent weight $(\mathrm{g})$.

Adsorption isotherm studies. In this study, the Freundlich and Langmuir adsorption isotherm models were used to determine the type of adsorption on the EFBBs; this was achieved by fitting the data to the Freundlich and Langmuir isotherm models. The correlation coefficient $\left(R^{2}\right)$ obtained from the isotherm plots were used to identify the isotherm models which best describe the adsorption of the $\mathrm{Pb}$ ion.

The Freundlich isotherm model. The linear form of the Freundlich equation is:

$$
\log Q_{\mathrm{e}}=\log K_{\mathrm{F}}+1 / n \log C_{\mathrm{e}}
$$

where $Q_{\mathrm{e}}$ is adsorbed weight of $\mathrm{Pb}$ ion per unit weight of adsorbent, $K_{\mathrm{F}}$ and $n$ are Freundlich empirical constants $\left(\mathrm{L} \mathrm{g}^{-1}\right)$ and $C_{\mathrm{e}}$ is the ion equilibrium concentration.

The Langmuir isotherm model. The linear Langmuir isotherm model used is: ${ }^{24}$

$$
\frac{C_{\mathrm{e}}}{Q_{\mathrm{e}}}=\frac{1}{b Q_{\max }}+\frac{C_{\mathrm{e}}}{Q_{\max }}
$$

where $Q_{\max }$ is the maximum adsorption capacity $\left(\mathrm{mg} \mathrm{g}^{-1}\right)$ of the $\mathrm{Pb}$ ion per unit weight of sorbent. The affinity of the metal for binding on the sorption sites is indicated by $b\left(\mathrm{~L} \mathrm{mg}^{-1}\right)$. The constant parameters of the Langmuir isotherm i.e. $Q_{\max }$ and $b$ can be calculated from the linear form of the Langmuir equation by plotting $C_{\mathrm{e}} / Q_{\mathrm{e}}$ versus $C_{\mathrm{e}}$. The separation factor $R_{\mathrm{L}}$, which is a dimensionless constant, was extracted from the Langmuir isotherm to predict whether an adsorption system is 'favourable' or 'unfavourable' as follows: ${ }^{25}$

$$
R_{\mathrm{L}}=\frac{1}{1+b C_{\mathrm{e}}}
$$

where $C_{\mathrm{e}}\left(\mathrm{mg} \mathrm{L}^{-1}\right)$ is the equilibrium concentration of $\mathrm{Pb}$ and $\mathrm{Cd}$ ions and $b\left(\mathrm{~mL} \mathrm{mg}^{-1}\right)$ is the affinity constant of the Langmuir isotherm model. The adsorption process as a function of $R_{\mathrm{L}}$ may be described as:

$R_{\mathrm{L}}>1$, unfavourable; $R_{\mathrm{L}}=1$, Linear; $0<R_{\mathrm{L}}<1$, favourable; and $R_{\mathrm{L}}=0$, irreversible.

\section{Statistical analysis}

Statistical analysis was carried out using SAS version 9.4 to determine significant differences in physicochemical properties between the different EFBB samples. 


\section{Results and discussion}

\section{Physical properties}

Field emission scanning electron microscopy (FESEM) surface analysis. It is important to study the morphological features of a solid material's surface to understand its geometric structure and particle shape. The micrographs of the three EFBB samples taken under $5000 \times$ magnification are shown in Fig. 1. The images depict the presence of macropores on the surface of the biochars and the decrease in pore size, M-EFBB $(14.457 \mu \mathrm{m})>$ C-EFBB $(4.742 \mu \mathrm{m})>$ F-EFBB $(0.459 \mu \mathrm{m})$. This finding is consistent with the BET analysis where M-EFBB had the largest pore volume (Table 1). The C-EFBB (Fig. 1c) had smaller pore diameters than the M-EFBB (Fig. 1b) which may be due to the bottleneck phenomenon as postulated by DieguezAlonso. ${ }^{12}$ Crushing the biochar will destroy this blockage and expose more pores with wider diameters as demonstrated by $\mathbf{M}$ EFBB. However, the results also show that the F-EFBB (Fig. 1a) had more inner pores exposed and the smallest diameter among all the biochars. Further crushing of the EFBB into particle size $<50 \mu \mathrm{m}$ may have destroyed the macropores, leaving mostly the meso- and micropores exposed. This may indicate that crushing the EFBB into smaller particles will increase pore diameters but when the particle size becomes $<50$ $\mu \mathrm{m}$, the macropores are destroyed leaving only the micropores and mesopores.

Crushing the EFBB to $<50 \mu \mathrm{m}$ significantly, the smaller size of pores exposed. The Electron Dispersive Spectroscopy (EDS) spectra (Fig. 2) revealed the dominant elements in the EFBB samples. The percentage of oxygen increased as the particle size was reduced, suggesting that crushing the EFBB sample to $<50$ $\mu \mathrm{m}$ particle size exposed the oxygen functional groups of the biochar. Even though the EDS spectra can only provide qualitative and semi-quantitative information regarding the elemental contents of the biochars, the data are well supported by the data of PZC (Fig. 4), CEC, total acidic functional groups, total oxygen content, $\mathrm{O} / \mathrm{C}$ ratio and $\mathrm{O}+\mathrm{N} / \mathrm{C}$ ratio (Table 1 ).

BET surface area analysis. Table 1 shows the BET surface area, total pore volume and the micropore surface area of the EFBB samples. The results indicate that the F-EFBB had the greatest surface area, followed by M-EFBB and C-EFBB with the lowest recorded. However, the $\mathrm{M}$-EFBB had the greatest pore volume, followed by F-EFBB and C-EFBB. The micropore surface area was only detected in the F-EFBB sample suggesting that micropores were present due to crushing the biochar to $<50 \mu \mathrm{m}$. This exposed the micropores and removed possible blockages of the macro pores by ash or volatile materials, i.e. the bottleneck phenomenon.
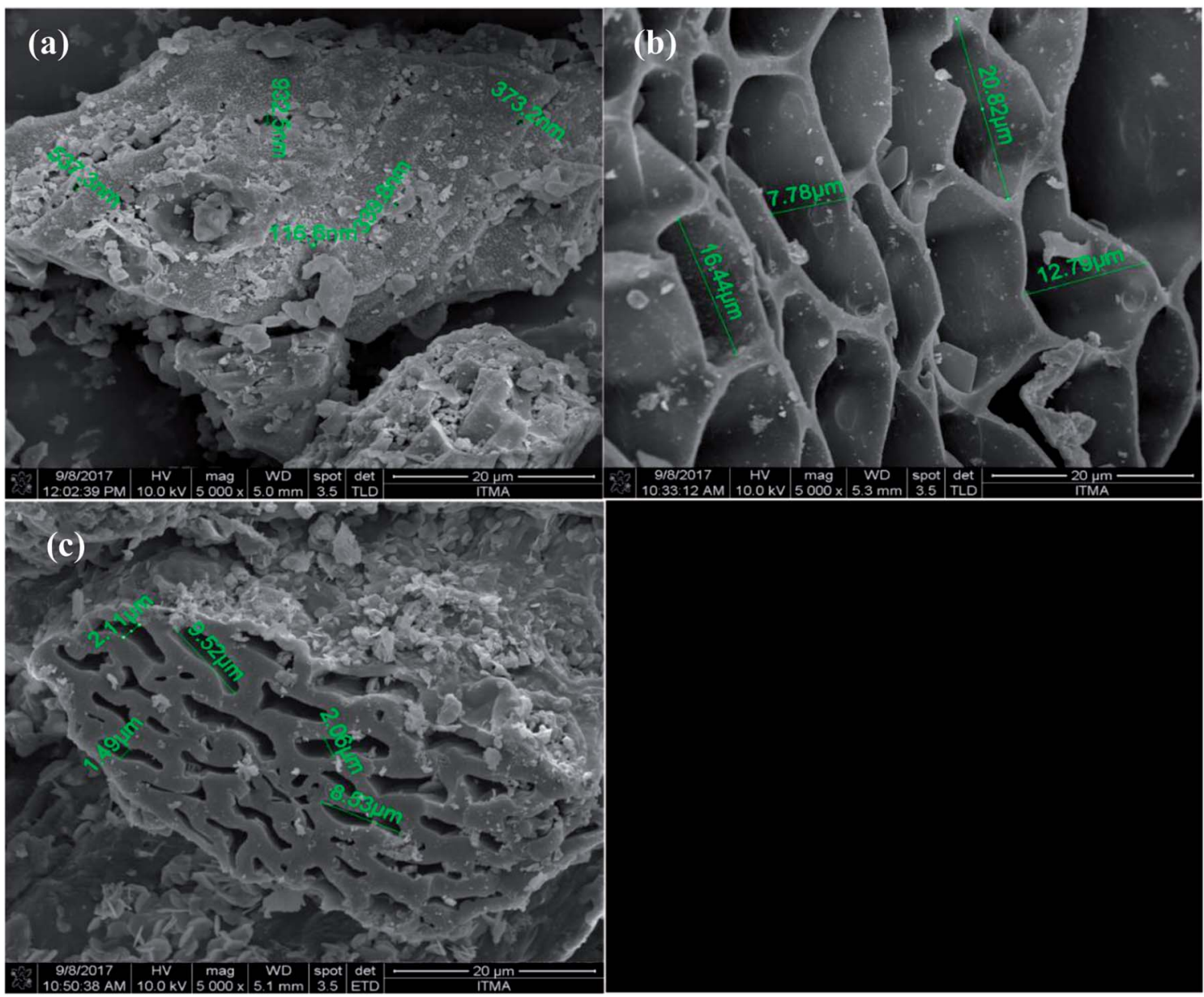

Fig. 1 FESEM images of (a) F-EFBB (b) M-EFBB and (c) C-EFBB. 
Table 1 The selected physicochemical characteristics of the EFBBs ${ }^{a}$

\begin{tabular}{|c|c|c|c|}
\hline Parameters & C-EFBB & M-EFBB & F-EFBB \\
\hline Ash content $(\%)$ & $15.383 \pm 0.066 a$ & $15.461 \pm 0.957 a$ & $14.771 \pm 0.043 a$ \\
\hline $\mathrm{pH}$ & $9.333 \pm 0.035 b$ & $9.360 \pm 0.02 b$ & $9.603 \pm 0.025 a$ \\
\hline Total C (\%) & $61.817 \pm 0.511 a$ & $61.817 \pm 0.511 a$ & $61.817 \pm 0.511 a$ \\
\hline $\mathrm{O}(\%)$ & $17.967 \pm 0.559 a$ & $17.860 \pm 0.484 a$ & $18.580 \pm 1.483 a$ \\
\hline $\mathrm{H}(\%)$ & $3.627 \pm 0.005 a$ & $3.627 \pm 0.005 a$ & $3.627 \pm 0.005 a$ \\
\hline $\mathrm{K}(\%)$ & $4.124 \pm 0.018 a$ & $4.124 \pm 0.018 a$ & $4.124 \pm 0.018 a$ \\
\hline $\mathrm{Si}(\%)$ & $0.048 \pm 0.003 a$ & $0.048 \pm 0.003 a$ & $0.048 \pm 0.003 a$ \\
\hline $\mathrm{H} / \mathrm{C}$ ratio & $0.058 \pm 0.000 a$ & $0.058 \pm 0.000 a$ & $0.058 \pm 0.000 a$ \\
\hline $\mathrm{O} / \mathrm{C}$ ratio & $0.290 \pm 0.011 a$ & $0.289 \pm 0.026 a$ & $0.301 \pm 0.010 a$ \\
\hline$(\mathrm{O}+\mathrm{N}) / \mathrm{C}$ ratio & $0.308 \pm 0.011 a$ & $0.307 \pm 0.026 a$ & $0.318 \pm 0.010 a$ \\
\hline $\mathrm{Al}(\%)$ & $0.044 \pm 0.003 a$ & $0.044 \pm 0.003 a$ & $0.044 \pm 0.003 a$ \\
\hline $\mathrm{Fe}(\%)$ & $0.159 \pm 0.002 a$ & $0.159 \pm 0.002 a$ & $0.159 \pm 0.002 a$ \\
\hline Total oxygen-containing functional groups $\left(\right.$ meq $\left.^{-1}\right)$ & $0.470 \pm 0.002 c$ & $0.475 \pm 0.008 b$ & $0.490 \pm 0.005 a$ \\
\hline OH group $\left(\right.$ meq g $\left.^{-1}\right)$ & $0.150 \pm 0.000 b$ & $0.152 \pm 0.002 a b$ & $0.153 \pm 0.001 a$ \\
\hline CO group $\left(\mathrm{meq} \mathrm{g}^{-1}\right)$ & $0.093 \pm 0.002 a$ & $0.092 \pm 0.004 a$ & $0.091 \pm 0.003 \mathrm{a}$ \\
\hline $\mathrm{COOH}$ group $\left(\mathrm{meq} \mathrm{g}^{-1}\right)$ & $0.227 \pm 0.002 b$ & $0.230 \pm 0.003 b$ & $0.245 \pm 0.002 \mathrm{a}$ \\
\hline $\left.\mathrm{CEC} \mathrm{cmol}_{+}\right) \mathrm{kg}^{-1}$ by $\left(\mathrm{BaCl}_{2}\right)$ & $1.842 \pm 0.506 c$ & $8.100 \pm 0.312 b$ & $16.464 \pm 0.280 \mathrm{a}$ \\
\hline BET surface area $\left(\mathrm{m}^{2} \mathrm{~g}^{-1}\right)$ & 0.90 & 1.70 & 2.57 \\
\hline Total pore volume $\left(\mathrm{cm}^{3} \mathrm{~g}^{-1}\right)$ & 0.239 & 0.327 & 0.285 \\
\hline Micropore surface area $\left(\mathrm{m}^{2} \mathrm{~g}^{-1}\right)$ & ND & ND & 2.533 \\
\hline
\end{tabular}

The larger pore diameters of the M-EFBB resulted in higher total pore volume when compared to C-EFBB (Table 1). The lower pore volume of C-EFBB could be due to blockage of the pores. ${ }^{10}$ According to Dieguez Alonso, ${ }^{\mathbf{1 2}}$ sample crushing is important to reduce pore diffusion limitations caused by the bottleneck phenomenon, especially for samples with micropores. The F-EFBB had more exposed inner pores, hence a higher surface area (Table 1).

The BET values reported in this study are in the range of values reported by previous researchers. ${ }^{26}$ The authors observed that the BET values of oak wood and oak bark biochars measured on dry samples was very small (1-3 $\left.\mathrm{m}^{2} \mathrm{~g}^{-1}\right)$ compared to commercial activated carbon $\left(\sim 1000 \mathrm{~m}^{2} \mathrm{~g}^{-1}\right)$. However, the maximum adsorption of $\mathrm{Cr}$ by these biochars were higher than the commercial activated carbon. The authors attributed this to the swelling of biochar in water and opening of pores and adsorption sites that were otherwise closed when biochar was dry, thus provided more internal adsorption sites for $\mathrm{Cr}$ adsorption. Moreover, the BET values of EFB biochars in this study are in the range as reported for EFBB biochar in other studies such as Yavari et al. ${ }^{27}\left(1.46 \mathrm{~m}^{2} \mathrm{~g}^{-1}\right)$ and Samsuri et al. ${ }^{13}$ $\left(1.890 \mathrm{~m}^{2} \mathrm{~g}^{-1}\right)$.

\section{Chemical properties}

pH and EC. The selected chemical properties of the EFBB samples are shown in Table 1. The $\mathrm{pH}$ of the F-EFBB was significantly higher than that of M-EFBB or C-EFBB. This result agrees with Shen et al. ${ }^{18}$ who reported an increase in $\mathrm{pH}$ as particle size was reduced. Several investigators ${ }^{13}$ suggested that biochar $\mathrm{pH}$ increases when minerals are separated from the carbon matrix of the biochar. A similar trend was observed for the EC values as the F-EFBB showed the highest EC followed by M-EFBB and C-EFBB. The presence of $\mathrm{K}$ and other elements as shown in the EDX data is most likely responsible for the high EC values of the EFBB samples.

Total carbon, hydrogen, nitrogen. The total carbon content value of all EFBB samples were similar, 61.82\% (Table 1). This value can be classified as a medium carbon content. ${ }^{6}$ The oxygen content (\%) differs among the EFBB samples but the differences were not significant. Even though the \% oxygen content of F-EFBB was not significantly different from M-EFBB and C-EFBB (Table 1), the \% oxygen content measured by the EDX showed that the F-EFBB had the highest value followed by M-EFBB and C-EFBB (Fig. 1). This indicates that crushing the EFBB to $<50 \mu \mathrm{m}$ particle size might have exposed the oxygen containing functional groups within the biochar matrix. The values for the $\mathrm{H} / \mathrm{C}$ ratio were similar for the three EFBB samples (0.058) and this value is close to the values reported by Samsuri et $a l .{ }^{13}$ for EFBB (0.08). The $\mathrm{H} / \mathrm{C}$ can be used as an indicator of biochar stability and the lower the value, the more stable the biochar. Biochars with an $\mathrm{H} / \mathrm{C}$ of less than 0.7 are considered stable and thermochemical altered. ${ }^{28}$ The $\mathrm{O} / \mathrm{C}$ ratio (hydrophilicity index) of biochar is used to indicate the abundance of oxygen-containing functional groups like the carboxyl group. ${ }^{29}$ 


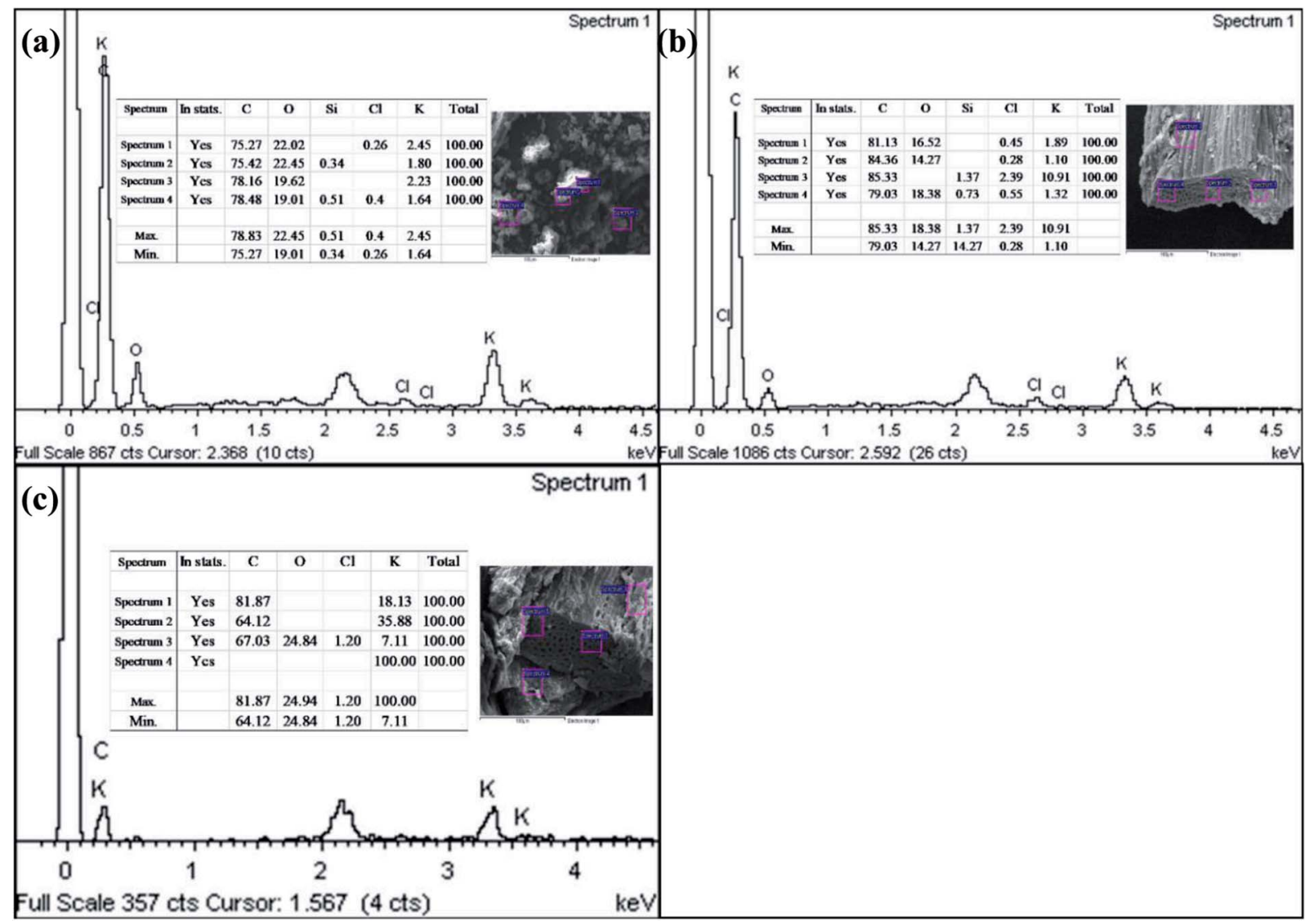

Fig. 2 FESEM-EDX spectra for (a) F-EFBB (b) M-EFBB and (c) C-EFBB.

The $\mathrm{O} / \mathrm{C}$ values for the EFBB samples were not significantly different (Table 1) and the values are similar to the values reported by Claoston et al. ${ }^{4}$ for EFBB produced at three different temperatures (0.33). There was no significant difference in the $(\mathrm{O}+\mathrm{N}) / \mathrm{C}$ values among the three EFBB samples.

Surface acidic groups. The total number of oxygencontaining functional groups and carboxyl groups $(\mathrm{COOH})$ were significantly higher in the F-EFBB than that in the M-EFBB and C-EFBB (Table 1), indicating that crushing the biochar to a particle size of $<50 \mu \mathrm{m}$ might have exposed the functional groups within the biochar matrix. Mohan et al. ${ }^{30}$ stated that the oxygen functional groups of biochar are in a solid matrix and are formed by thermal decomposition of the hemicellulose, cellulose and lignin of the biomass. Therefore, crushing the biochars to $<50 \mu \mathrm{m}$ led to the exposure of a larger proportion of surface functional groups in the biochars. Hence, the adsorption capacity of the crushed biochar was enhanced as the newly exposed sites can provide more surface active sites for heavy metal adsorption. ${ }^{31}$ However, there was no significant difference in the number of $\mathrm{CO}$ groups among the EFBBs.

Cation exchange capacity. The F-EFBB had significantly higher CEC than M-EFBB and C-EFBB, a result consistent with Shen et al..$^{18}$ who reported an increase in CEC values as biochar particle size decreased from $2 \mathrm{~mm}$ to $0.15 \mathrm{~mm}\left(5.62 \mathrm{cmol}_{+} \mathrm{kg}^{-1}\right.$ and $7.20 \mathrm{cmol}_{+} \mathrm{kg}^{-1}$, respectively). The higher CEC of the FEFBB can be attributed to the presence of higher oxygen containing functional groups such as carboxyl. ${ }^{32}$ Particle size reduction, which may have exposed the inner pores of the FEFBB, may have resulted in more oxygen functional groups in the F-EFBB. It has been reported that biochars contain functional groups in the unexposed inner pores. ${ }^{33}$

Fourier transform infrared spectroscopy (FTIR) analysis. The spectra of the EFBB samples (Fig. 3) show peaks in the regions $3248,3172,2900,1567,1301,1060$ and $737 \mathrm{~cm}^{-1}$ corresponding to $\mathrm{O}-\mathrm{H}$ stretch, $\mathrm{O}-\mathrm{H}$ stretch, $\mathrm{C}-\mathrm{H},-\mathrm{COOH}, \mathrm{C}-\mathrm{O}, \mathrm{C}-\mathrm{O}$ stretch, and $\mathrm{COO}^{-}$stretch, respectively. ${ }^{34-37}$ It can be inferred that the functional groups present in the EFBB samples shared similar peak assignments, but the peaks for F-EFBB were of greater intensity.

Zeta potential. The point of zero charge (PZC) for the EFBB samples varied (Fig. 4). At the $\mathrm{pH} 2$, the zeta potentials of EFBB samples were $-3.03 \mathrm{mV}, 0.256 \mathrm{mV}$ and $0.257 \mathrm{mV}$ for F-EFBB, MEFBB and C-EFBB, respectively, with the values becoming more negative with increasing $\mathrm{pH}$ values. The PZC for the C-EFBB (Fig. 4) was 2.07, indicating that the surface of the C-EFBB has a net negative charge at a $\mathrm{pH}>2.07$, and at a $\mathrm{pH}<2.07$ the surface of the C-EFBB has a net positive charge. The PZC slightly increased to 2.16 for the M-EFBB (Fig. 4) sample. However, the PZC was not detected for F-EFBB at all measured pH ranges (Fig. 4) which implies the surfaces were all negatively charged regardless of $\mathrm{pH}$, which is also consistent with its greatest CEC value. This indicates that reducing the EFBB 


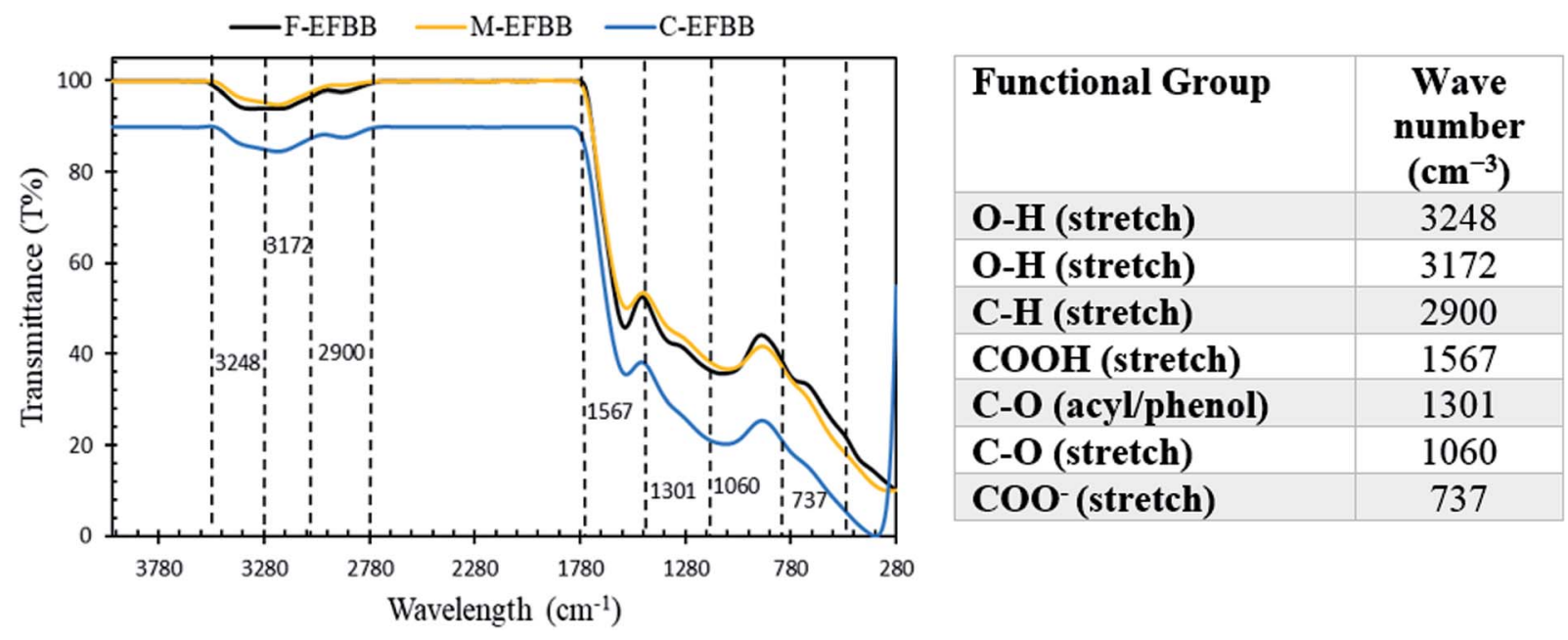

Fig. 3 FTIR spectra of the EFBB samples and the functional groups present.

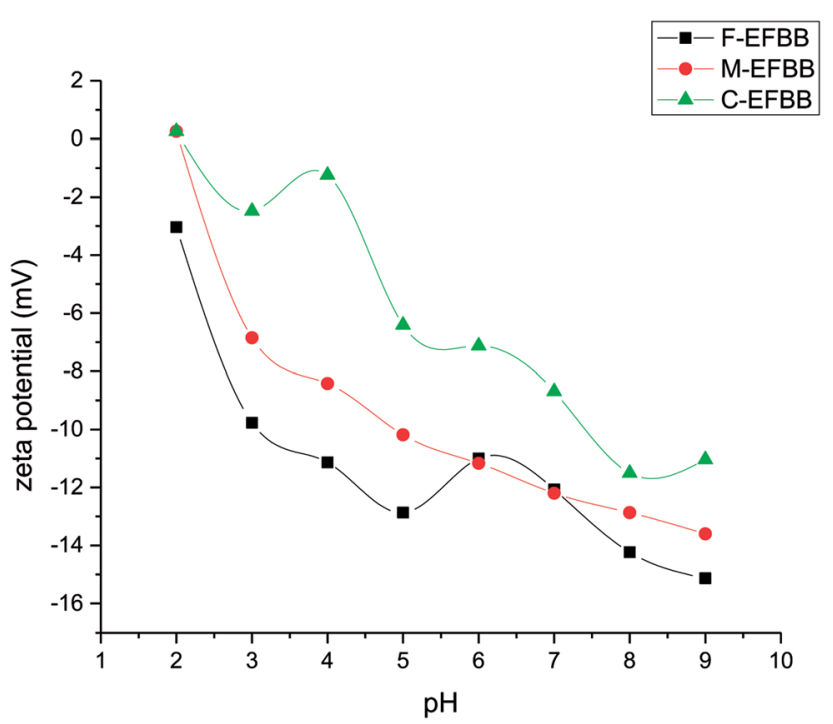

Fig. 4 The zeta potential as a function of $\mathrm{pH}$ for F-EFBB, M-EFBB, and C-EFBB.

particle size to $<50 \mu \mathrm{m}$ exposed the functional groups of the inner pores.

The F-EFBB had the highest percentage of oxygen, acidic functional groups, CEC and zeta potential (lower PZC) which indicates that crushing the EFBB to $<50 \mu \mathrm{m}$ had exposed the functional groups within the biochar matrix and the inner pores. According to Mohan et al. ${ }^{15}$ the functional groups are found throughout the matrix of the biochar. The exposure of surface functional groups in the F-EFBB increased the surface negative charges and lowered the PZC. Studies have indicated that adsorption of metal ions in a solution occurs only if the surface of the adsorbent is negatively charged ${ }^{4,16}$ and adsorption is more effective when the adsorbent has low PZC. ${ }^{38}$

Adsorption of $\mathbf{P b}$ by the EFBBs. The sorption isotherms of $\mathrm{Pb}$ by EFBBs can be classified as an $\mathrm{H}$ type curve (Fig. 5), indicating that the sorbate has a high affinity for the adsorbent surfaces. ${ }^{39,40}$ The adsorption capacity of C-EFBB, M-EFBB and FEFBB grew with increasing $\mathrm{Pb}$ concentrations. because as the initial $\mathrm{Pb}$ concentrations increased, the driving force in the concentration gradient did as well. The adsorption capacity almost levelled off at higher concentrations indicating an equilibrium occurred between the sorbate and the adsorption sites.

Adsorption isotherms. In this study, the adsorption data of the $\mathrm{Pb}$ ion by the EFBBs were fitted to the Freundlich (eqn (4)) and Langmuir (eqn (5)) isotherm models. The data for the sorption of $\mathrm{Pb}$ by C-EFBB, M-EFBB and F-EFBB were a better fit with the Langmuir adsorption as indicated by the $R^{2}$ values (Table 2) (Fig. 6). The adsorption isotherm fitted the Langmuir model, inferring the interaction of $\mathrm{Pb}$ to the biochar surface was chemical in nature. ${ }^{41}$ The Langmuir model assumes a monolayer sorption occurs between the sorbate and homogenous

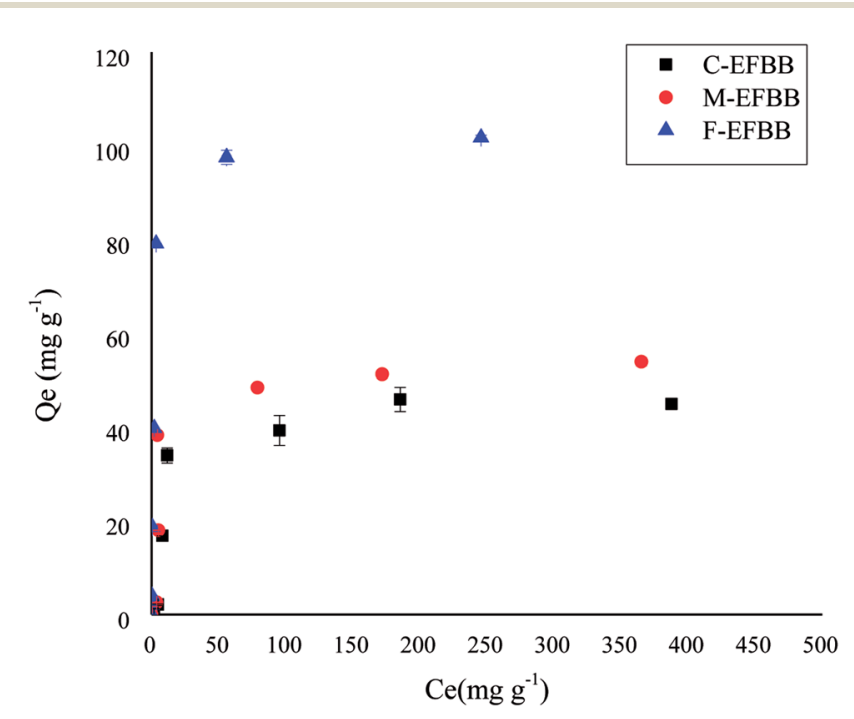

Fig. 5 The amounts of $\mathrm{Pb}$ adsorbed by the coarse biochar (C-EFBB), medium biochar (M-EFBB) and fine biochar (F-EFBB) from aqueous solutions at different concentrations. 
Table 2 Langmuir and Freundlich isotherm parameters and correlation coefficients for the adsorption of Pb on the EFBBs

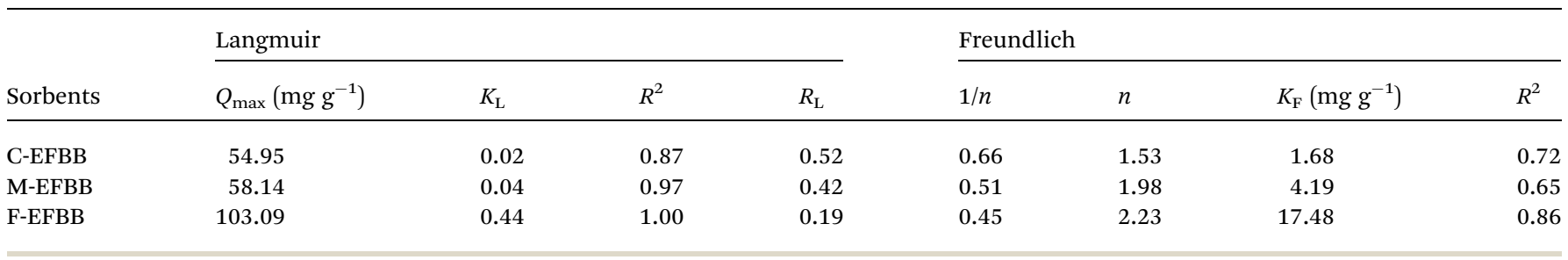

surfaces of the adsorbent. The $K_{\mathrm{L}}$ in the Langmuir model is the binding energy coefficient and the value for F-EFBB was higher than M-EFBB and C-EFBB (Table 2), indicating that F-EFBB had a greater affinity for the $\mathrm{Pb}^{2+}$ ion than M-EFBB and C-EFBB. This was due to the exposure of more functional groups within the inner pores of the biochar matrix, which led to more effective interaction between these functional groups with $\mathrm{Pb}^{2+}$. Previous studies also used a binding constant, $K_{\mathrm{L}}$, to estimate the interaction between sorbate and adsorbent. ${ }^{42,43}$ With respect to the Langmuir isotherm, the sorption capacity for $\mathrm{Pb}$ by the adsorbents generally follows the order, F-EFBB $>$ M-EFBB $>$ C-EFBB. Similarly, the same trend was observed for the Freundlich sorption isotherm. The adsorption capacity for $\mathrm{Pb}$ was highest in the F-EFBB, followed by the M-EFBB then C-EFBB. The values of the separation factor $\left(R_{\mathrm{L}}\right)$ can be used to indicate the nature of the adsorption process. They are classified as unfavourable when $R_{\mathrm{L}}>1$, linear when $R_{\mathrm{L}}=1$, and favourable when $0<R_{\mathrm{L}}<1$. A value of 0 indicates an irreversible process. In this study, the $R_{\mathrm{L}}$ values ranged from 0.19 to 0.52 , indicating that the adsorption process was favourable for all the samples (Table 2). These values are also consistent with the $R_{\mathrm{L}}$ values reported by Kołodyńska et al. ${ }^{44}$ and Claoston ${ }^{45}$ who studied the adsorption of $\mathrm{Pb}$ by biochars. The values of the Freundlich adsorption intensity, $n$, ranged from 2.23 to 1.53 (Table 2). Based on these values the adsorption between sorbents and $\mathrm{Pb}$ is favourable and the interaction that occurred between $\mathrm{Pb}$ and F-EFBB was stronger compared to other adsorbents (M-EFBB and C-EFBB). Kumar et al. ${ }^{46}$ and Goswami et al. ${ }^{47}$ stated that the adsorption between sorbent and adsorbate is favourable when the $n$ value range was 1 to 10 and the higher $n$ value (smaller value of $1 / n$ ) indicates a stronger interaction occurred between them.

The adsorption capacities of the F-EFBB for $\mathrm{Pb}$ was greater than the values of EFBB reported by Samsuri $e t a l .^{13}$ which were $58.8 \mathrm{mg} \mathrm{g}^{-1}$. This may be due to the fine particle size $(<50 \mu \mathrm{m})$ used in the present study. The high adsorption capacity for heavy metals can be attributed to the functional group, zeta potential and CEC. ${ }^{13}$ This also explains the greater sorption capacity exhibited by the F-EFBB in the present study. The increasing adsorption capacity for $\mathrm{Pb}$ (Table 2) with decreasing particle size indicates that crushing the EFBB into finer particles may have exposed the inner pores (Fig. 1 and Table 1) and therefore, increased the presence of oxygen functional groups and CEC (Table 1) of the biochar while lowering the zeta potential (Fig. 4). The present study suggested that particle size reduction led to the exposure of the inner pores containing additional organic functional groups which could increase metal binding by the biochars. This also explains the greater sorption capacity exhibited by the F-EFBB. The higher adsorption capacity of the finer particle size for $\mathrm{Pb}$ is consistent with the study by Kołodyńska et al. ${ }^{44}$ who reported the adsorption of heavy metals increased with the decreasing particle size of biochars. Shen et al. ${ }^{18}$ compared adsorption of $\mathrm{Pb}$ by biochars of 0.15 and $2 \mathrm{~mm}$ particle size and found higher adsorption capacity in the $0.15 \mathrm{~mm}$ biochar. They attributed this to the greater surface area and CEC of the smaller particle size biochar. The FESEM-EDX analysis (Fig. 7) confirmed adsorption of $\mathrm{Pb}$ had occurred on the adsorbent.
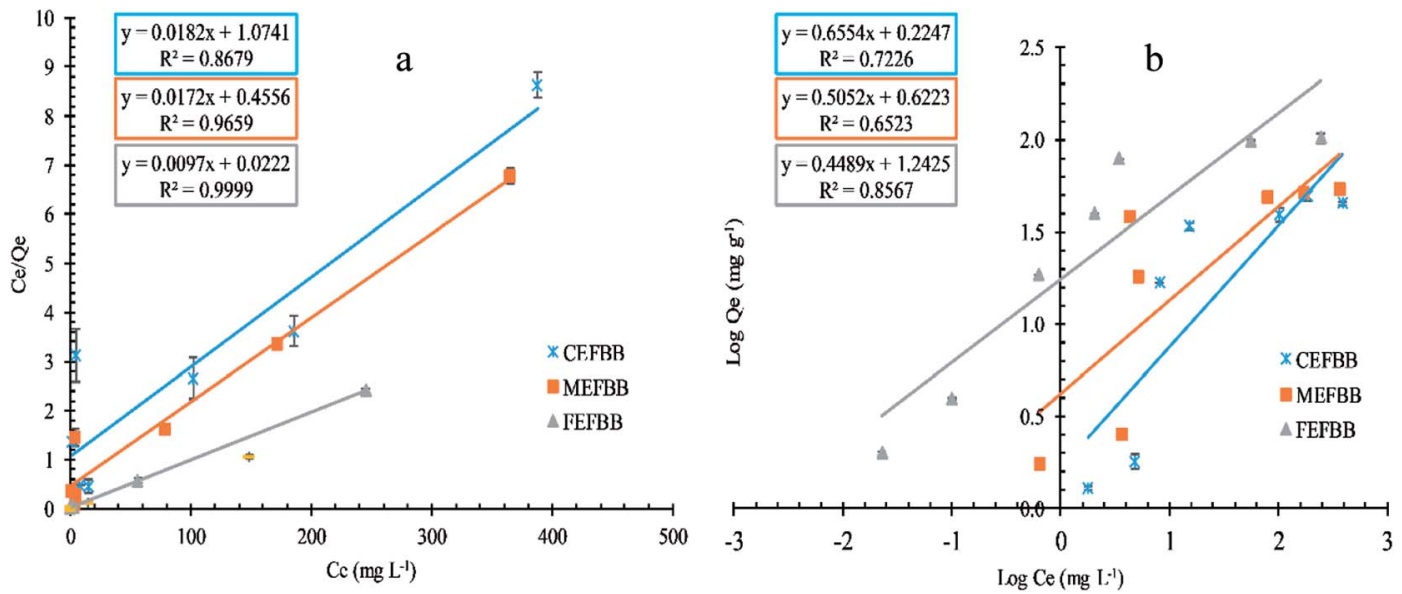

Fig. 6 Effect of concentration on the adsorption capacities of EFBBs towards Pb ion ((a) the Langmuir isotherm, (b) the Freundlich isotherm). 


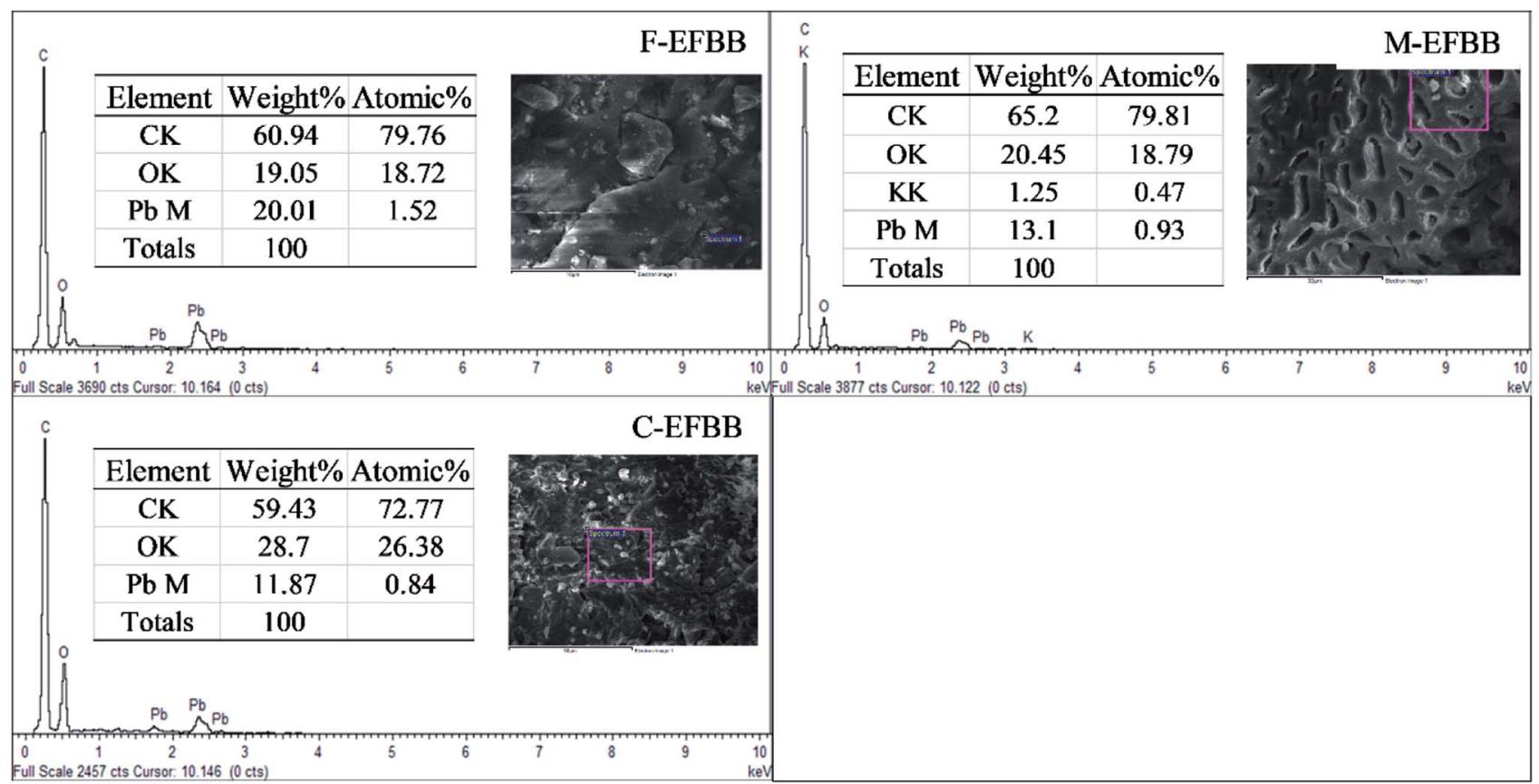

Fig. 7 EDX spectra after adsorption Pb by EFBBs.

Adsorption mechanisms. Li et $a l .{ }^{48}$ proposed that the main adsorption mechanisms for heavy metal adsorption by biochars are cation exchange, complexation and precipitation. The amount of cations $\left(\mathrm{Ca}^{2+}, \mathrm{Mg}^{2+}\right.$ and $\left.\mathrm{K}^{+}\right)$released from F-EFBB, $\mathrm{M}$ EFBB and C-EFBB in the $\mathrm{Pb}^{2+}$ adsorption process indicate that ion exchange is the major mechanism for adsorption in EFBBs (Table 3). The amount of $\mathrm{Ca}^{2+}, \mathrm{Mg}^{2+}$ and $\mathrm{K}^{+}$released from the adsorbents were higher in the aqueous solution with $500 \mathrm{mg}$ $\mathrm{kg}^{-1} \mathrm{~Pb}$ compared to an aqueous solution of $0 \mathrm{mg} \mathrm{kg}^{-1} \mathrm{~Pb}$ due to the exchange of $\mathrm{Pb}$ with these cations on adsorption sites. Depending on the stoichiometric reaction, the equivalent amount (mmol) of cations exchanged were equal to the equivalent amount (mmol) of $\mathrm{Pb}$ adsorbed. Therefore, the ion exchange mechanism accounted for $72.65 \%, 87.78 \%$ and $78.01 \%$ of the adsorption of Pb by the F-EFBB, M-EFBB and CEFBB, respectively (Table 3). Therefore, it can be confirmed the ion exchange mechanism was the dominant mechanism occurring in EFBBs (Table 3). The results of the current study are consistent with the results reported by Ding et al. ${ }^{49}$ The authors found that the ion exchange mechanism played an important role in adsorption of heavy metals by biochar produced at low temperatures compared to biochar pyrolysis at high temperatures due to the lack of functional groups present. They stated that intraparticle diffusion was the dominate mechanism for metal adsorption by biochars produced by higher temperature pyrolysis. Lu et al. ${ }^{50}$ and Zhang et al. ${ }^{51}$ also speculated that the ion exchange mechanism was responsible for the $\mathrm{Pb}$ adsorption process by biochar pyrolysis at $450{ }^{\circ} \mathrm{C}$ and $550{ }^{\circ} \mathrm{C}$.

The release of cations into the solution from the adsorbents increased the solution $\mathrm{pH}$ as shown in the $0 \mathrm{mg} \mathrm{L}^{-1} \mathrm{~Pb}$ solution (Table 4). This is consistent with the results previously reported by other researchers. ${ }^{48,52}$ However, the $\mathrm{pH}$ of a solution containing $500 \mathrm{mg} \mathrm{L}^{-1} \mathrm{~Pb}$ decreased after the $\mathrm{Pb}$ was adsorbed by the adsorbents (Table 4). This can prove that deprotonation of functional groups had occurred. The reduction in $\mathrm{pH}$ varied among the adsorbents. This variation could be due to differences in the content and the degree of functional group exposure among the adsorbents. Therefore, the reduction in $\mathrm{pH}$ was more significant with F-EFBB than M-EFBB or C-EFBB (Table 4) due to the higher content of functional groups in the former adsorbents. Therefore, it can be concluded that complexation

Table 3 The release of cation in aqueous solution during adsorbed $\mathrm{Pb}$ by EFBBs and \% ion exchange mechanism ${ }^{a}$

\begin{tabular}{|c|c|c|c|c|c|}
\hline F-EFBB & $47.587 \pm 0.275$ & $106.381 \pm 0.506$ & $58.793 \pm 0.587$ & $80.927 \pm 0.348$ & $72.65 \%$ \\
\hline C-EFBB & $43.074 \pm 0.298$ & $77.073 \pm 0.264$ & $33.998 \pm 0.559$ & $43.607 \pm 0.827$ & $78.01 \%$ \\
\hline
\end{tabular}

${ }^{a}$ Values represent means of $(n=3)$. No S.E. 
Table 4 The changing of $\mathrm{pH}$ value after adsorbed $\mathrm{Pb}$ by the EFBBs in aqueous solution ${ }^{a}$

\begin{tabular}{llll}
\hline Sorbents & pH of $0 \mathrm{mg} \mathrm{L}^{-1} \mathrm{~Pb}$ solution & $\begin{array}{l}\text { pH of } 500 \mathrm{mg} \mathrm{L}^{-1} \mathrm{~Pb} \\
\text { solution }\end{array}$ & \multicolumn{1}{c}{ Differences } \\
\hline F-EFBB & $9.400 \pm 0.015$ & $5.963 \pm 0.007$ & $3.437 \pm 0.014$ \\
M-EFBB & $9.473 \pm 0.031$ & $6.367 \pm 0.021$ & $3.107 \pm 0.018$ \\
C-EFBB & $8.927 \pm 0.098$ & $5.830 \pm 0.146$ & $3.097 \pm 0.107$
\end{tabular}

${ }^{a}$ Values represent means of $(n=3)$. No S.E.

had occurred between the functional groups of the adsorbents, especially F-EFBB and the metals. This result is also evidence that crushing the EFBB exposed the functional groups of the inner pores within the biochar matrix. The $\mathrm{pH}$ reduction in the solution was more pronounced with the F-EFBB compared to the M-EFBB and C-EFBB.

The XRD diffractograms (Fig. 8) show peaks at $2 \theta^{\circ}: 37.9,2 \theta^{\circ}$ : 20.77 and 32 , and $2 \theta^{\circ}: 27.21$ which indicate the presence of $\mathrm{Pb}_{3}\left(\mathrm{CO}_{3}\right)_{2}(\mathrm{OH})_{2},{ }^{53} \mathrm{~Pb}_{9}\left(\mathrm{PO}_{4}\right)_{6}$, and $\mathrm{Pb}_{3}\left(\mathrm{CO}_{3}\right)(\mathrm{OH}),{ }^{54}$ respectively. However, all the XRD diffractograms show similar peak intensities suggesting that precipitation mechanism was not the reason for the increasing adsorption capacity of biochar for $\mathrm{Pb}$ with decreasing particle sizes.

The results suggest that EFBBs can be used for remediation of acidic soils contaminated with heavy metals due to the high adsorption capacity of the EFBBs for the metals as well as their ability to release nutrients $(\mathrm{K}, \mathrm{Ca}, \mathrm{Mg}$ ) for plant growth and increasing soil $\mathrm{pH}$ and CEC.

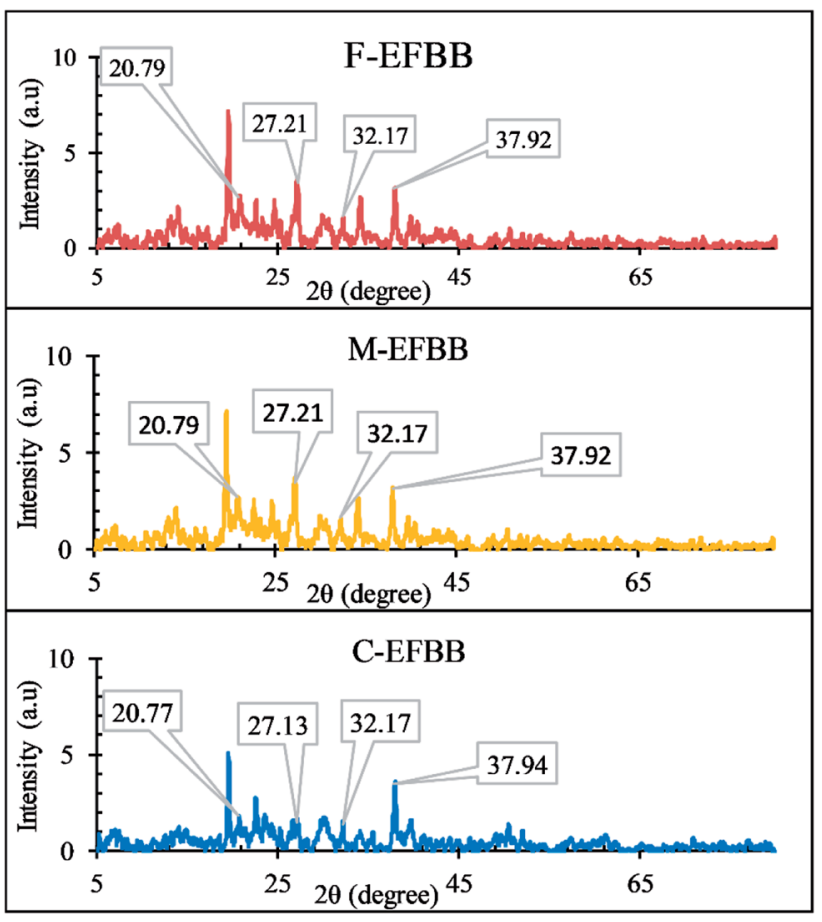

Fig. 8 The XRD diffractograms after adsorption of $\mathrm{Pb}$ by the EFBBs.

\section{Conclusions}

The physical modification to EFBB by crushing it into smaller particle sizes significantly improved its physicochemical properties. The inner pores and functional groups of EFBB were exposed when crushed to $<50 \mu \mathrm{m}$ (F-EFBB). The F-EFBB had the highest BET surface area, micropore surface area, pH, CEC, functional groups, negative charge on the surface and the lowest PZC value. The F-EFBB had the highest adsorption capacity for $\mathrm{Pb}$ followed by M-EFBB and the lowest was C-EFBB. Therefore, the results of this study suggest that crushing the EFBB to $<50 \mu \mathrm{m}$ is recommended to increase its adsorption capacity for heavy metals.

\section{Conflict of interest}

All the authors declared no conflict of interest in conducting this research and no human being or animal was used for experimental purposes in this study.

\section{Acknowledgements}

The authors would like to thank Universiti Putra Malaysia for providing a research grant to conduct this research under the UPM/IPS/9575800 Research Grant. The authors also would like to acknowledge the University of Diyala for providing a $\mathrm{PhD}$ scholarship to the first author.

\section{References}

1 P. Kosolsaksakul, I. W. Oliver and M. C. Graham, J. Environ. Manage., 2018, 215, 49-56.

2 S. P. Sohi, Science, 2012, 338, 1034-1035.

3 C. N. B. Yong Sik Ok, M. Sophie and X. Uchimiya Scott, Biochar Production, Characterization, and Applications, CRC press, 2015.

4 N. Claoston, A. Samsuri, M. Ahmad Husni and M. Mohd Amran, Waste Manag. Res., 2014, 32, 331-339.

5 L. C. O. A. Melo, A. R. Coscione, C. A. Abreu, A. P. Puga and O. A. Camargo, BioResources, 2013, 8, 4992-5004.

$6 \mathrm{~J}$. Lehmann and S. Joseph, Biochar for environmental management: science, technology and implementation, Routledge, 2015.

7 D. W. Rutherford, R. L. Wershaw and J. B. Reeves III, US Geolegical Surv., 2008, p. 43. 
8 L. Kong, Y. Xiong, L. Sun, S. Tian, X. Xu, C. Zhao, R. Luo, X. Yang, K. Shih and H. Liu, J. Hazard. Mater., 2014, 274, 205-211.

9 X. Cao, L. Ma, B. Gao and W. Harris, Environ. Sci. Technol., 2009, 43, 3285-3291.

10 M. Uchimiya, L. H. Wartelle, K. T. Klasson, C. A. Fortier and I. M. Lima, J. Agric. Food Chem., 2011, 59, 2501-2510.

11 K. T. Klasson, M. Uchimiya, I. M. Lima, K. Thomas Klasson, M. Uchimiya and I. M. Lima, Chemosphere, 2014, 111, 129134.

12 A. Dieguez-Alonso, Fixed-bed biomass pyrolysis: mechanisms and biochar production, Dr.-Ing Dissertation, Tecnische Universitat, Berlin, 2015.

13 A. W. Samsuri, F. Sadegh-Zadeh and B. J. Seh-Bardan, Int. J. Environ. Sci. Technol., 2014, 11, 967-976.

14 J. Wang and C. Chen, Biotechnol. Adv., 2006, 24, 427-451.

15 D. Mohan, P. Singh, A. Sarswat, P. H. Steele and C. U. Pittman Jr, J. Colloid Interface Sci., 2015, 448, 238-250.

16 L. Trakal, D. Bingöl, M. Poholvrel $\backslash^{`} y$, M. Hruška and M. Komárek, Bioresour. Technol., 2014, 171, 442-451.

17 M. Thommes, K. Kaneko, A. V Neimark, J. P. Olivier, F. Rodriguez-Reinoso, J. Rouquerol and K. S. W. Sing, Pure Appl. Chem., 2015, 87, 1051-1069.

18 Z. Shen, F. Jin, F. Wang, O. McMillan and A. Al-Tabbaa, Bioresour. Technol., 2015, 193, 553-556.

19 Z. Shen, O. McMillan, F. Jin and A. Al-Tabbaa, J. Hazard. Mater., 2016, 316, 214-220.

20 D. Savova, E. Apak, E. Ekinci, F. Yardim, N. Petrov, T. Budinova, M. Razvigorova and V. Minkova, Biomass Bioenergy, 2001, 21, 133-142.

21 W. Song and M. Guo, J. Anal. Appl. Pyrolysis, 2012, 94, 138145.

22 S. P. McGrath and C. H. Cunliffe, J. Sci. Food Agric., 1985, 36, 794-798.

23 G. P. Gillman and E. A. Sumpter, Soil Res., 1986, 24, 61-66.

24 J. O. Azeez, S. O. Obanla, A. O. Ojo and A. O. Shokalu, Commun. Soil Sci. Plant Anal., 2010, 41, 108-121.

25 K. Y. Foo and B. H. Hameed, Chem. Eng. J., 2010, 156, 2-10.

26 D. Mohan, S. Rajput, V. K. Singh, P. H. Steele and C. U. Pittman, J. Hazard. Mater., 2011, 188, 319-333.

27 S. Yavari, A. Malakahmad, N. B. Sapari and S. Yavari, J. Environ. Manage., 2017, 193, 201-210.

28 IBI, IBI biochar Stand., 2015, pp. 1-61.

29 Y. Chun, G. Sheng, C. T. Chiou and B. Xing, Environ. Sci. Technol., 2004, 38, 4649-4655.

30 D. Mohan, P. Singh, A. Sarswat, P. H. Steele and C. U. Pittman, J. Colloid Interface Sci., 2015, 448, 238-250.

31 W. J. Liu, H. Jiang and H. Q. Yu, Chem. Rev., 2015, 115, 12251-12285.
32 B. Singh, B. P. Singh and A. L. Cowie, Soil Res., 2010, 48, 516525.

33 J. E. Amonette and S. Joseph, Characteristics of biochar: microchemical properties, in Biochar for environmental management: Science and technology, Earthscan, London, UK, 2009, vol. 33.

34 S. Ricordel, S. Taha, I. Cisse and G. Dorange, Sep. Purif. Technol., 2001, 24, 389-401.

35 X. Tong, J. Li, J. Yuan and R. Xu, Chem. Eng. J., 2011, 172, 828-834.

36 J. Ifthikar, J. Wang, Q. Wang, T. Wang, H. Wang, A. Khan, A. Jawad, T. Sun, X. Jiao and Z. Chen, Bioresour. Technol., 2017, 238, 399-406.

37 D. Kołodyńska, J. Krukowska and P. Thomas, Chem. Eng. J., 2017, 307, 353-363.

38 R. C. Bansal and M. Goyal, Activated carbon adsorption, CRC press, 2005.

39 C. H. Giles, D. Smith and A. Huitson, J. Colloid Interface Sci., 1974, 47, 755-765.

40 K. H. Tan, Principles of Soil Chemistry, 2010, vol. 18.

41 D. Tiwari, H. U. Kim and S. M. Lee, Sep. Purif. Technol., 2007, 57, 11-16.

42 X. Ma, X. Liu, D. P. Anderson and P. R. Chang, Food Chem., 2015, 181, 133-139.

43 T. Ma, P. R. Chang, P. Zheng, F. Zhao and X. Ma, Chem. Eng. J., 2014, 240, 595-600.

44 D. Kołodyńska, R. Wn $\backslash$ ketrzak, J. J. Leahy, M. H. B. Hayes, W. Kwapiński and Z. Hubicki, Chem. Eng. J., 2012, 197, 295-305.

45 A. N. Claoston, Immobilisation of arsenic, copper, manganese and lead in gold mine tailings by oil palm empty fruit bunch and rice husk biochars, Master's thesis, Universiti Putra Malaysia, 2015.

46 A. S. K. Kumar, T. Gupta, S. S. Kakan, S. Kalidhasan, V. Rajesh, N. Rajesh and others, J. Hazard. Mater., 2012, 239, 213-224.

47 R. Goswami, J. Shim, S. Deka, D. Kumari, R. Kataki and M. Kumar, Ecol. Eng., 2016, 97, 444-451.

48 H. Li, X. Dong, E. B. da Silva, L. M. de Oliveira, Y. Chen and L. Q. Ma, Chemosphere, 2017, 178, 466-478.

49 W. Ding, X. Dong, I. M. Ime, B. Gao and L. Q. Ma, Chemosphere, 2014, 105, 68-74.

50 H. Lu, W. Zhang, Y. Yang, X. Huang, S. Wang and R. Qiu, Water Res., 2012, 46, 854-862.

51 F. Zhang, X. Wang, D. Yin, B. Peng, C. Tan, Y. Liu, X. Tan and S. Wu, J. Environ. Manage., 2015, 153, 68-73.

52 L. Qian and B. Chen, J. Agric. Food Chem., 2014, 62, 373-380. 53 E. F. Zama, Y. G. Zhu, B. J. Reid and G. X. Sun, J. Cleaner Prod., 2017, 148, 127-136.

54 X. Xu, X. Cao and L. Zhao, Chemosphere, 2013, 92, 955-961. 